RESPIRATORY INFECTION

\title{
Antibiotic treatment and factors influencing short and long term outcomes of acute exacerbations of chronic bronchitis
}

\author{
R Wilson, P Jones, T Schaberg, P Arvis, I Duprat-Lomon, P P Sagnier, for the MOSAIC \\ Study Group
}

See end of article for authors' affiliations

Correspondence to: Dr R Wilson, Royal Brompton Hospital, Sydney Street, London SW3 6NP, UK; r.wilson@ rbht.nhs.uk

Received 29 April 2005 Accepted 30 December 2005 Published Online First 31 January 2006
Background: The MOSAIC study compared moxifloxacin with three standard antibiotic regimens in patients with Anthonisen type 1 acute exacerbations of chronic bronchitis (AECB). Further exploratory analyses were performed to identify prognostic factors of short and long term clinical outcomes and their value for clinical research.

Methods: Outpatients aged $\geqslant 45$ years were screened between $A E C B$ episodes, randomised to treatment upon presenting with an $A E C B$, assessed 7-10 days after study treatment, and followed monthly until a new $A E C B$ or for up to 9 months. Logistic regression assessed the predictive factors for clinical cure (return to pre-AECB status) and clinical success (cure or improvement), and a stepwise Cox regression model time to a composite event (failure of study treatment, new $A E C B$, or further antibiotic treatment for $A E C B$ ).

Results: In multivariate analyses, clinical cure was positively influenced by treatment with moxifloxacin lodds ratio (OR) $1.49 ; 95 \% \mathrm{Cl} 1.08$ to 2.04 ) while cardiopulmonary disease (OR $0.59 ; 95 \% \mathrm{Cl} 0.38$ to $0.90)$, forced expiratory volume in 1 second $\left(\mathrm{FEV}_{1}\right)<50 \%$ predicted $(\mathrm{OR} 0.48 ; 95 \% \mathrm{Cl} 0.35$ to 0.67 ), and $\geqslant 4 \mathrm{AECBs}$ in the previous year (OR $0.68 ; 95 \% \mathrm{Cl} 0.48$ to 0.97 ) predicted a poorer outcome. For clinical success, treatment with moxifloxacin had a positive influence (OR $1.57 ; 95 \% \mathrm{Cl} 1.03$ to 2.41 ) while cardiopulmonary disease (OR $0.41 ; 95 \% \mathrm{Cl} 0.25$ to 0.68 ) and use of acute bronchodilators (OR 0.50; $95 \% \mathrm{Cl} 0.30$ to 0.84 ) predicted a poorer outcome. The occurrence of the composite event was influenced by antibiotic treatment (hazard ratio (HR) $0.82 ; 95 \% \mathrm{Cl} 0.68$ to 0.98 ), age $\geqslant 65$ years (HR $1.22 ; 95 \% \mathrm{Cl}$ 1.01 to 1.47 ), $\mathrm{FEV}_{1}<50 \%$ predicted (HR $1.27 ; 95 \% \mathrm{Cl} 1.05$ to 1.53 ), $\geqslant 4 \mathrm{AECBs}$ in previous year (HR $1.63 ; 95 \% \mathrm{Cl} 1.34$ to 1.99 ), and acute bronchodilator use (HR $1.48 ; 95 \% \mathrm{Cl} 1.17$ to 1.87 ). For the composite event the beneficial effect of moxifloxacin was primarily seen in patients aged $\geqslant 65$ years. Conclusion: Despite selection of a homogeneous population of patients with chronic bronchitis, between group differences relating to antibiotic treatment could still be confounded by factors related to medical history, severity of disease, and use of concomitant medications. The design of future clinical trials should take these factors into account.
$\mathrm{T}$ here is increasing evidence for the role of bacterial infection in causing acute exacerbations of chronic obstructive pulmonary disease (COPD), particularly in patients with chronic bronchitis who present with all three cardinal symptoms defined by Anthonisen et al. ${ }^{1}$ The frequency of exacerbations adversely affects disease progression and overall health status. ${ }^{2-4}$ Studies involving sputum analysis, bronchoscopic sampling, molecular epidemiology of bacterial strains, and immunology have linked the presence of bacterial infection with acute exacerbations of COPD and bacterial eradication with recovery. ${ }^{5-10}$ Chronic inflammation has been associated with bacterial persistence and the number of bacteria present in the airway with disease progression. ${ }^{11-14}$

It is therefore surprising that the benefits of antibiotic treatment of exacerbations have not been more clearly defined..$^{15}$ Most guidelines have used the Anthonisen criteria to decide when an antibiotic should be prescribed, but little evidence is available of efficacy differences between antibiotics. ${ }^{15}$ In view of the marked increase in the prevalence of bacterial strains resistant to antibiotics such as amoxicillin, tetracycline and erythromycin, the recently published Canadian guidelines have attempted to define at risk patients who might benefit from newly developed antibiotics that are active against resistant strains. ${ }^{151718}$
In a meta-analysis of placebo controlled trials of acute exacerbations of COPD, antibiotic treatment had a small but significant benefit on overall recovery and change in peak flow. ${ }^{19}$ However, most antibiotic trials have compared one antibiotic with another. These trials usually evaluated the short term outcome, defined as improvement in signs and symptoms sufficient to make further antibiotic prescription unnecessary. They compared antibiotic regimens in heterogeneous populations with poorly defined disease severity and most studies were underpowered to demonstrate superiority. ${ }^{15}$ In this context, they have almost all shown clinical equivalence, even when one antibiotic has shown better bacteriological eradication. ${ }^{15} 20$ This discrepancy could have several explanations. Most airway infections causing acute exacerbations of COPD are superficial although mucosal invasion can occur, and efficient host defences lead to high spontaneous recovery rates. ${ }^{121}$ The opportunity to show differences between antibiotics may be greater in patients with more severe disease or in those with risk factors for a poor outcome. ${ }^{15}{ }^{22}$ Patients with persistent bacterial infection due to ineffective antibiotic treatment might improve by reducing bacterial numbers, but their recovery may be

Abbreviations: $A E C B$, acute exacerbation of chronic bronchitis; $B M I$, body mass index; $\mathrm{FEV}_{1}$, forced expiratory volume in 1 second 
incomplete and they could have a more rapid relapse. ${ }^{11}$ Long term follow up might therefore reveal differences in efficacy between antibiotics.

The MOSAIC study was designed to meet these shortcomings. ${ }^{22}$ This large trial compared the short and long term outcomes of antibiotic treatments in patients with chronic bronchitis with a history of heavy smoking and significant lung function impairment. Moxifloxacin showed clinical equivalence to standard treatment for clinical success (the primary outcome measure) and achieved superior clinical cure rates (defined as a return to baseline health status) and significantly higher bacteriological eradication rates than standard treatment. Fewer patients required additional antimicrobial drugs in the weeks following the exacerbation and the time to the next acute exacerbation of chronic bronchitis (AECB) was significantly longer after treatment with moxifloxacin. In the analysis of a composite end point comprising treatment failure, a new exacerbation, or the need for a further antibiotic for lower respiratory tract illness, moxifloxacin was shown to be significantly superior for up to 5 months of follow up.

The superiority of moxifloxacin shown in these secondary outcomes could be due to more successful bacteriological eradication leading to resolution of bronchial inflammation, a complete return to baseline symptoms, fewer rapid relapses requiring antibiotic treatment, and a longer time to the next exacerbation. We have investigated which clinical features were associated with the short and long term treatment outcomes and have looked at the results of antibiotic treatments in these subgroups to see whether the differences between moxifloxacin and comparator antibiotics were increased or reduced.

\section{METHODS \\ Design}

The design and primary outcomes of this prospective, randomised, double blind study have been reported previously. ${ }^{22}$ Outpatients aged $\geqslant 45$ years with documented chronic bronchitis were eligible for enrolment during an AECB free period if they had a history of cigarette smoking of at least 20 pack years, two or more documented AECBs in the previous year, and forced expiratory volume in 1 second $\left(\mathrm{FEV}_{1}\right)<85 \%$ of predicted at the enrolment visit. Patients then presenting with an Anthonisen type 1 AECB were randomised to receive either treatment with moxifloxacin (400 mg once daily for 5 days) or one of the following comparators chosen by the investigators: amoxicillin (500 mg three times daily for 7 days), clarithromycin (500 mg twice daily for 7 days), or cefuroxime-axetil (250 mg twice daily for 7 days).

The study protocol was approved by the ethics committees and patients provided their written informed consent.

\section{End points}

Short term results were assessed on the clinical response evaluated by the investigators 7-10 days after the end of treatment. They included clinical success (defined as sufficient improvement in signs and symptoms so that the patient did not require any alternative antimicrobial treatment) and clinical cure (defined as a complete return to pre-exacerbation state of health). The long term measurement was a composite event defined as the time to treatment failure, occurrence of a new exacerbation, or any antibiotic use for a further AECB during the 9 month follow up period.

\section{Factors}

The present post hoc and exploratory analyses were conducted in the intent-to-treat (ITT) population. Factors with potential impact on the clinical outcomes were selected according to the literature. ${ }^{23-30}$ They were age $(<65$ or $\geqslant 65$ years), body mass index (BMI) $\leqslant 30 \mathrm{~kg} / \mathrm{m}^{2}$ or $>30 \mathrm{~kg}$ / $\mathrm{m}^{2}$, sex, current smoking status, alcohol consumption, comorbidities (diabetes mellitus, coexistent cardiopulmonary disease), severity of chronic bronchitis (number of AECBs in the previous year $(2-3$ or $\geqslant 4)$, and $\mathrm{FEV}_{1}(<50 \% v \geqslant 50 \%$ of predicted value at enrolment)), duration of chronic bronchitis $(<10$ or $\geqslant 10$ years $)$, time elapsed since previous AECB ( $<6$ or $\geqslant 6$ months), and concomitant medications (steroids, bronchodilators). "No steroid administration" was defined as no steroid use at randomisation or no increase in long term steroid dosage; long term inhaled steroids administered for more than 2 months before randomisation and/or systemic steroids started at randomisation or increased dosage at randomisation if previously administered were classified as "steroid administration". Bronchodilator administration was defined as the use of any bronchodilator type during the

\begin{tabular}{|c|c|c|c|c|}
\hline & \multicolumn{2}{|l|}{ Clinical cure } & \multirow{2}{*}{$\begin{array}{l}\text { Selected } \\
\text { subjects } \\
(\mathrm{N}=730)\end{array}$} & \multirow[b]{2}{*}{ p value* } \\
\hline & $\begin{array}{l}\text { No } \\
(N=243)\end{array}$ & $\begin{array}{l}\text { Yes } \\
(\mathrm{N}=487)\end{array}$ & & \\
\hline Treatment & & & & 0.020 \\
\hline Comparator & $140(37 \%)$ & $236(63 \%)$ & 376 & \\
\hline Moxifloxacin & $103(29 \%)$ & $251(71 \%)$ & 354 & \\
\hline Steroid use & & & & 0.014 \\
\hline No & $88(28 \%)$ & $223(72 \%)$ & 311 & \\
\hline Yes & $155(37 \%)$ & $264(63 \%)$ & 419 & \\
\hline Cardiopulmonary disease & & & & $\leqslant 0.001$ \\
\hline No & $193(31 \%)$ & $432(69 \%)$ & 625 & \\
\hline Yes & $50(48 \%)$ & $55(52 \%)$ & 105 & \\
\hline $\mathrm{FEV}_{1}(\%)$ at enrolment & & & & $\leqslant 0.001$ \\
\hline$\geqslant 50$ & $109(26 \%)$ & $313(74 \%)$ & 422 & \\
\hline$<50$ & $134(44 \%)$ & $174(56 \%)$ & 308 & \\
\hline Number of $A E C B s$ in previous year & & & & 0.019 \\
\hline $2-3$ & $162(31 \%)$ & $365(69 \%)$ & 527 & \\
\hline$\geqslant 4$ & $81(40 \%)$ & $122(60 \%)$ & 203 & \\
\hline Time elapsed from previous $A E C B$ & & & & 0.035 \\
\hline$>6$ months & $122(30 \%)$ & $285(70 \%)$ & 407 & \\
\hline$\leqslant 6$ months & $120(37 \%)$ & $201(63 \%)$ & 321 & \\
\hline
\end{tabular}


Table 2 Prognostic factors associated with the clinical cure rate 7-10 days after the end of treatment using a stepwise logistic model (ITT population)

\begin{tabular}{|c|c|c|c|c|}
\hline \multirow[b]{2}{*}{ Parameter } & \multirow[b]{2}{*}{ Odds ratio } & \multirow[b]{2}{*}{ Probability } & \multicolumn{2}{|c|}{$95 \%$ Confidence interval } \\
\hline & & & Lower limit & Upper limit \\
\hline $\begin{array}{l}\text { Treatment }(0=\text { comparator; } 1=\text { moxifloxacin }) \\
\text { Cardiopulmonary disease }(0=\text { no; } 1=\text { yes }) \\
\mathrm{FEV}_{1}(\%) \text { at enrolment }(0=\geqslant 50 ; 1=<50) \\
\text { Number of } \mathrm{AECB} \text { in previous year }(0=2-3 ; 1=\geqslant 4)\end{array}$ & $\begin{array}{l}1.485 \\
0.585 \\
0.482 \\
0.684\end{array}$ & $\begin{array}{l}0.015 \\
0.016 \\
<0.001 \\
0.032\end{array}$ & $\begin{array}{l}1.079 \\
0.378 \\
0.349 \\
0.483\end{array}$ & $\begin{array}{l}2.044 \\
0.903 \\
0.666 \\
0.967\end{array}$ \\
\hline
\end{tabular}

acute phase (the period between randomisation and 710 days after end of treatment) and included short acting and long acting $\beta$ agonists and/or anticholinergic agents.

\section{Analysis of data}

The association between each individual prognostic factor and clinical outcomes (clinical cure, clinical success, and composite end point) was tested by $\chi^{2}$ tests. The independent prognostic contributions of individual factors to the clinical outcomes were then tested by multivariate stepwise logistic regression analyses for clinical cure and clinical success, respectively. Because the composite end point was the timedependent variable, the multivariate analysis used a stepwise Cox regression model. The threshold for statistical significance was $\mathrm{p}=0.05$. Interactions between treatment and prognostic factors were then tested for the factors found to be significant in the multivariate analyses using a threshold of $p=0.10$. When the interaction test was inferior to that threshold, the between treatment difference at each level was described. The statistical software packages SAS Windows Versions 6.12 and 8.2 were used.

\section{RESULTS}

A full description of the patients studied $(n=730)$ and their randomisation is given in table $\mathrm{S} I$ available online at http:// www.thoraxjnl.com/supplemental. The mean (SD) age was 63.2 (9.8) years, $42.3 \%$ had $\mathrm{FEV}_{1}<50 \%, 27.7 \%$ had $\geqslant 4$ exacerbations in the previous year, and the mean (SD) time since diagnosis of chronic bronchitis was 12.5 (0.8) years. There was no significant difference in these values between the two arms of the study.

\section{Clinical cure}

The factors identified in the univariate analysis were antibiotic treatment, steroid use, cardiopulmonary diseases, $\mathrm{FEV}_{1}$, number of previous AECBs, and time elapsed from previous AECB. All other factors were not statistically significant (table 1). When a multivariate logistic model was applied, moxifloxacin was independently associated with a higher clinical cure rate than the comparator drugs while co-morbid cardiopulmonary disease, $\mathrm{FEV}_{1}<50 \%$ predicted, and $\geqslant 4$ AECBs in the previous year had a detrimental effect on the outcome (table 2).

\section{Clinical success}

Steroid use $(p=0.043)$, co-morbid cardiopulmonary disease $(\mathrm{p}=0.002), \mathrm{FEV}_{1}<50 \%$ predicted $(\mathrm{p}=0.006)$, and acute use of bronchodilators $(\mathrm{p}=0.028)$ were significant factors in the univariate analysis. All other factors were not significant. A full analysis of the prognostic analysis for clinical success is given in table S3 available online at http://www.thoraxjnl. com/supplemental. In the multivariate model, moxifloxacin was significantly better than the comparator drugs (OR 1.573 (95\% CI 1.028 to 2.408 ); $p=0.037$ ) while cardiopulmonary disease (OR 0.410 (95\% CI 0.246 to 0.683 ); $p<0.001$ ) and use of acute bronchodilators (OR 0.497 (95\% CI 0.296 to 0.835 ); $\mathrm{p}=0.008$ ) were detrimental independent predictive factors of outcomes. There was no interaction between treatment and either of the individual factors (cardiopulmonary, $\mathrm{p}=0.274$; use of acute bronchodilators, $\mathrm{p}=0.794$ ).

\section{Long term outcome}

In univariate analyses the factors that had a significant impact on the occurrence of the composite event were $\geqslant 4$ AECBs in the previous year and use of acute bronchodilators (table 3). In the multivariate model, antibiotic treatment, age $\geqslant 65$ years, $\mathrm{FEV}_{1}<50 \%$ predicted, $\geqslant 4$ AECBs in the previous year, and acute bronchodilator use had a statistically significant effect on long term outcome (table 4).

Moxifloxacin had a beneficial effect compared with comparator treatment on the occurrence of the composite event $(\mathrm{OR}=0.816)$, while other significant factors had a

\begin{tabular}{|c|c|c|c|c|}
\hline & \multicolumn{2}{|c|}{ Composite event } & \multirow{2}{*}{$\begin{array}{l}\text { Selected } \\
\text { subjects } \\
(\mathrm{N}=730)\end{array}$} & \multirow[b]{2}{*}{ p value ${ }^{*}$} \\
\hline & $\begin{array}{l}\text { No } \\
(N=271)\end{array}$ & $\begin{array}{l}\text { Yes } \\
(\mathrm{N}=459)\end{array}$ & & \\
\hline Age (years) & & & & 0.072 \\
\hline$<65$ & $155(40 \%)$ & $231(60 \%)$ & 386 & \\
\hline$\geqslant 65$ & $116(34 \%)$ & $228(71 \%)$ & 344 & \\
\hline Number of $A E C B s$ in previous year & & & & $\leqslant 0.001$ \\
\hline $2-3$ & $220(42 \%)$ & $307(58 \%)$ & 527 & \\
\hline$\geqslant 4$ & $51(25 \%)$ & $152(75 \%)$ & 203 & \\
\hline Bronchodilators & & & & $\leqslant 0.001$ \\
\hline No & 247 (40\%) & $371(60 \%)$ & 618 & \\
\hline Yes & $24(21 \%)$ & $88(79 \%)$ & 112 & \\
\hline
\end{tabular}


Table 4 Independent prognostic factors for occurrence of the composite event using a stepwise Cox model (ITT population)

\begin{tabular}{|c|c|c|c|c|}
\hline \multirow[b]{2}{*}{ Parameter } & \multirow[b]{2}{*}{ Hazard ratio } & \multirow[b]{2}{*}{ Probability } & \multicolumn{2}{|c|}{$95 \%$ Confidence interval } \\
\hline & & & Lower limit & Upper limit \\
\hline Treatment $(0=$ comparator $; 1=$ moxifloxacin $)$ & 0.816 & 0.031 & 0.678 & 0.982 \\
\hline Age $(0=<65$ years; $1=\geqslant 65$ years $)$ & 1.219 & 0.039 & 1.010 & 1.470 \\
\hline $\mathrm{FEV}_{1}(\%)$ at enrolment $(0=\geqslant 50 ; 1=<50)$ & 1.265 & 0.014 & 1.048 & 1.526 \\
\hline Number of previous AECBs $(0=2-3 ; 1=\geqslant 4)$ & 1.631 & $<0.001$ & 1.338 & 1.988 \\
\hline Bronchodilators $(0=$ no; $1=$ yes $)$ & 1.477 & 0.001 & 1.166 & 1.872 \\
\hline
\end{tabular}

There was no interaction between treatment and any of the individual factors (age, $p=0.080 ; F E V_{1}, p=0.505$; number of previous $A E C B s, p=0.247$; acute bronchodilators, $\mathrm{p}=0.752$ ).

detrimental effect. The favourable effect of moxifloxacin was primarily linked to benefits in the subgroup of patients aged $\geqslant 65$ years $(p=0.015$, fig 1$)$. The global interaction term including the number of AECBs was not significant, but there was a significant difference in favour of moxifloxacin in the subgroup of patients who had $\geqslant 4$ AECBs in the previous year $(p=0.047$, fig 2$)$. Neither $\mathrm{FEV}_{1}$ nor acute bronchodilator use had an effect on the difference between antibiotic treatments.

\section{DISCUSSION}

The MOSAIC study has provided the opportunity to examine, in a systematic manner, the relative prognostic value of a number of factors related to medical history, clinical and functional status, and concomitant medications. Many factors identified in the univariate analysis were not retained in the multivariate analysis because of the large degree of covariation between the individual factors.

The findings of this post hoc analysis are similar to the published evidence that severity of airflow destruction, coexisting cardiopulmonary disease, and the frequency of previous exacerbations are risk factors for poorer short term outcomes. ${ }^{23-30}$ The number of previous AECBs appeared to have a more powerful influence than age and duration of the disease, probably because repeated exacerbations are linked to disease progression. While having cardiopulmonary
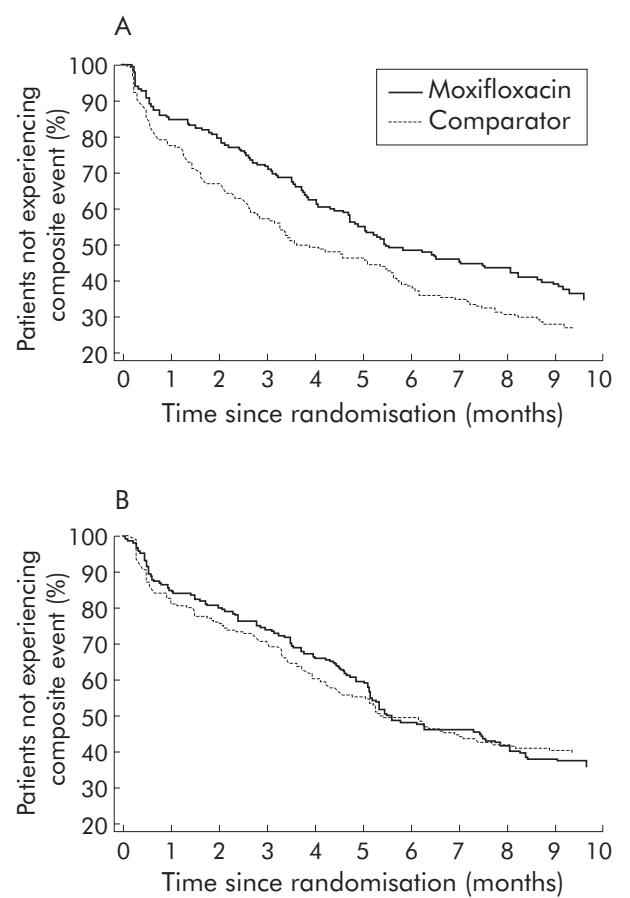

Figure 1 Life table analysis of time to the first composite event in $(A)$ patients aged $\geqslant 65$ years and (B) patients aged $<65$ years (intention-totreat population). disease as a co-morbid illness was a potent negative predictor of short term outcome, BMI $\leqslant 30 \mathrm{~kg} / \mathrm{m}^{2}$ and diabetes had no effect.

Current smoking has previously been associated with lower bacterial colonisation of the airway, but in this study it had no effect on either clinical cure or clinical success. ${ }^{31}{ }^{32}$ This discrepancy could be due to the homogeneity of the study population and the lack of a reference group of non-smokers. In fact, patients enrolled in the MOSAIC study were selected to increase the likelihood that bacterial infection was the cause of their exacerbation. They had to have the three cardinal symptoms of an Anthonisen type 1 exacerbationincluding increased breathlessness and sputum production, purulent sputum, and a long history of chronic bronchitis due to cigarette smoking. ${ }^{122} \mathrm{FEV}_{1}<50 \%$ predicted, the use of corticosteroids, and the use of bronchodilators were all negative predictive factors of outcomes (the latter solely on clinical success) in univariate analyses. However, in the multivariate analysis, the use of corticosteroids was no longer an independent predictive factor. This is probably explained by the high co-variation between these factors.

Regarding the long term outcome, Ball et $a l^{24}$ have shown that a past history of frequent exacerbations makes a future exacerbation more likely, a finding that is fully confirmed by
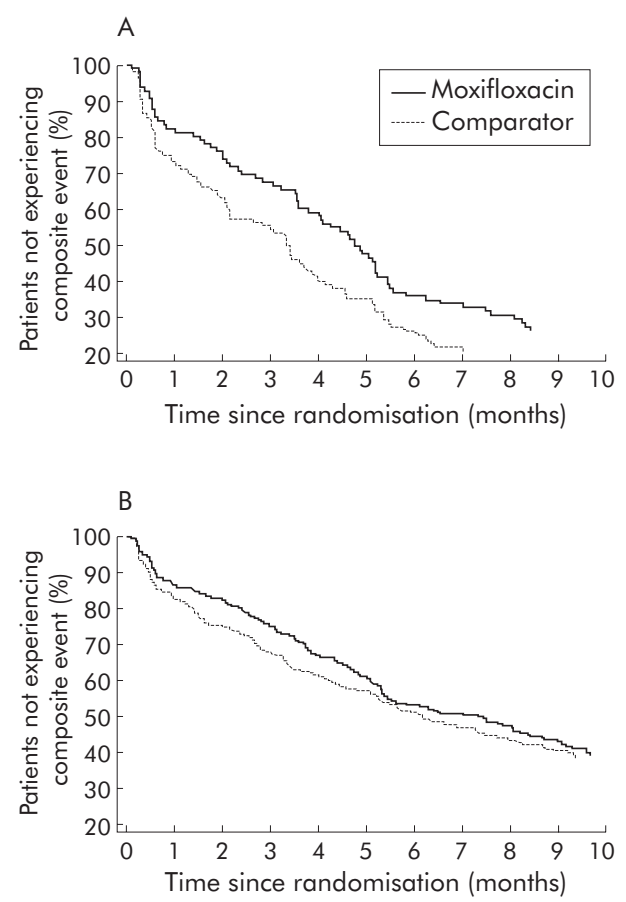

Figure 2 Life table analysis of time to the first composite event in (A) patients with $\geqslant 4$ previous acute exacerbations of chronic bronchitis (AECBs) and (B) patients with 2-3 previous AECBs (intention-to-treat population). 
the present study. Some patients are prone to frequent exacerbations, perhaps because their bronchial inflammation is poorly controlled and chronic bacterial infection may be the primary cause. ${ }^{13}$ Incomplete resolution of the index exacerbation, possibly due to persistent bacterial infection, would be expected to lead to a shorter interval before the next exacerbation. ${ }^{511}$ This hypothesis has led to the use of "time until next exacerbation" being used as a clinical end point in antibiotic trials. ${ }^{22}{ }^{33}$ The use of moxifloxacin and gemifloxacin has resulted in a longer time before the next exacerbation than clarithromycin (a macrolide antibiotic) and older betalactam antibiotics. However, this has not been the outcome in all such comparator studies, and the severity of the exacerbation at enrolment and the patient's underlying disease may account for these differences. For example, in the study by Lode et $a^{34}$ which did not find a difference in time until next exacerbation between levofloxacin and clarithromycin, a third of the patients were non-smokers (compared with none in the MOSAIC study), a quarter had $\mathrm{FEV}_{1}<50 \%$ (compared with $42 \%$ in the MOSAIC study), and a quarter had Anthonisen type 2 exacerbations (all patients in the MOSAIC study had type 1 exacerbations).

Similarly, $\mathrm{FEV}_{1}<50 \%$ predicted and acute use of bronchodilators appeared to be independent negative predictors of the long term outcome while the use of corticosteroids had no predictive value. The clinical findings of this post hoc analysis must be interpreted with caution, given the exploratory nature of the analysis and the fact that the use of corticosteroids and bronchodilators was not randomised. In the MOSAIC study the use of bronchodilators and/or corticosteroids, together with impaired $\mathrm{FEV}_{1}$, identified a patient subgroup at higher risk of failure; further research is needed to determine which of these three parameters has the best prognostic value in clinical practice. The data also suggest that the use of bronchodilators, most probably to treat wheezing, might be a direct or indirect marker of disease severity which influences the short and long term outcomes of antibiotic treatment, a hypothesis that could only be further tested in a randomised factorial design.

Another feature of the design of this study requires further consideration. The features of the exacerbation leading to antibiotic randomisation are defined by the Anthonisen type 1 criteria to capture a group of patients judged most likely to benefit from antibiotics. ${ }^{1}$ In the MOSAIC trial this was not true of the definition of treatment failure, nor of the next exacerbation, which were dependent on the doctor's judgement of the need for further antibiotic treatment. This clinical decision might have been made because of features such as level of breathlessness resulting from conditions other than bacterial infection. The early separation of the plots shown in figs $1 \mathrm{~A}$ and $2 \mathrm{~A}$ suggest that the main long term differences between the two study groups were primarily accrued in the first 6 weeks, perhaps due to persistence of bacterial infection. This time period therefore requires careful study to examine the reasons for clinical failure and the type of exacerbation that occurs with early recurrence following antibiotic treatment.

This analysis also sheds new light on the previously published clinical results of the MOSAIC study, in that the overall beneficial effect of moxifloxacin on clinical resolution was confirmed when prognostic factors were taken into account. When using the less stringent clinical outcome criterion of clinical success (that is, clinical resolution and improvement combined), the primary unadjusted analysis of the trial did not show a significant result. ${ }^{22}$ Interestingly, the subsequent statistical adjustment of prognostic factors unveiled a statistically significant difference between the two antibiotic treatment groups in favour of moxifloxacin. Likewise, in the primary analysis, moxifloxacin was found to have a beneficial effect on the occurrence of the composite event in the first 5 months of follow up, a difference that was no longer significant at completion of the study. ${ }^{22}$ The present post hoc analysis indicates that the beneficial effect of moxifloxacin was, in fact, sustained over the entire follow up period when relevant prognostic factors were taken into account. The benefit was primarily seen in two subsets of the study population-those aged $\geqslant 65$ years and those who had experienced $\geqslant 4$ exacerbations in the previous year. This information could be used in the design of future prospective studies using time to next exacerbation as the primary end point.

Overall, this study showed that the number of previous AECBs and the baseline $\mathrm{FEV}_{1}$ level were potent prognostic factors of the short and long term treatment outcomes of AECB. Co-morbid cardiopulmonary diseases appeared to have a negative effect on the short term outcome, although no explanation for this can be determined from the present analysis. The acute use of bronchodilators indicated a population at higher risk of failure in the longer term. Despite the choice of a homogeneous population of patients with chronic bronchitis from the MOSAIC study and stratification of the randomisation on corticosteroid use, between group differences could still be confounded by underlying factors related to the medical history, the severity of the disease, and to the use of concomitant medications. It suggests that future clinical trials of antibiotic treatment in AECB should systematically take these factors into account either a priori (at randomisation) or a posteriori (statistical analysis) in order to increase the sensitivity of the studies to detect differences between antibiotic regimens.

\section{ACKNOWLEDGEMENTS}

The authors thank Ms Nylani Liyanage and Dr Andreas Zipfel, Biometry Department, Bayer Health Care, and Dr Dominique Moyse, Consultant in Statistics, DM Consultant, Paris for their help with the statistical analysis of this study.

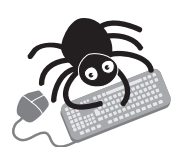

Further details of the patients studied, randomisation, and full analyses are given in tables S1-S4 in the online supplement available at http://www.thoraxinl. com/supplemental

\section{Authors' affiliations \\ R Wilson, Royal Brompton Hospital, London, UK \\ P Jones, Respiratory Medicine, St George's Hospital Medical School, London, UK \\ T Schaberg, Zentrum für Pneumologie, Diakoniekrankenhaus, Rotenburg, Germany \\ P Arvis, I Duprat-Lomon, Medical Affairs, Bayer Pharma, Puteaux, France \\ P P Sagnier, Global Health Economics and Reimbursement, Bayer Plc, Uxbridge, UK}

The study was sponsored by Bayer Health Care Pharma, Wuppertal, Germany.

Robert Wilson, Paul Jones and Tom Schaberg have acted as consultants and developed presentations for the sponsor for which they have received honoraria. Pierre Arvis, Isabelle Duprat-Lomon and PierrePhilippe Sagnier are sponsor staff members.

\section{REFERENCES}

1 Anthonisen NR, Manfreda J, Warren CP, et al. Antibiotic therapy in exacerbations of chronic obstructive pulmonary disease. Ann Intern Med 1987; 106:196-204.

2 Kanner RE, Anthonisen NR, Connett JE, et al. Lower respiratory illnesses promote $\mathrm{FEV}_{1}$ decline in current smokers but not ex-smokers with mild chronic obstructive pulmonary disease. Am J Respir Crit Care Med

2001;164:358-64. 
3 Donaldson GC, Seemungal TAR, Bhowmik A, et al. Relationship between exacerbation frequency and lung function decline in chronic obstructive pulmonary disease. Thorax 2002;57:847-52.

4 Spencer S, Jones PW. Time course of recovery of health status following an infective exacerbation of chronic bronchitis. Thorax 2003:58:589-93.

5 Patel IS, Seemungal TA, Wilks M, et al. Relationship between bacteria colonisation and the frequency, character and severity of COPD exacerbations. Thorax 2002;57:759-64.

6 Sethi S, Evans N, Grant B, et al. New strains of bacteria and exacerbations of chronic obstructive pulmonary disease. N Engl J Med 2002;347:465-71.

7 Monso E, Ruiz J, Rosell A, et al. Bacterial infection in chronic obstructive airways disease: a study of stable and exacerbated patients using the protected specimen brush. Am J Respir Crit Care Med 1995;152:1316-20.

8 Pela R, Marchesani F, Agostinelli C, et al. Airway microbial flora in COPD patients in stable clinical conditions and during exacerbations: a bronchoscopic investigation. Monaldi Arch Chest Dis 1998;53:262-7.

9 Soler N, Ewig S, Torres A, et al. Airway inflammation and bronchial microbial patterns in patients with stable chronic obstructive pulmonary disease. Eur Respir J 1999; 14:1015-22.

10 Sethi S, Wrona C, Grant BJB, et al. Strain-specific immune response to Haemophilus influenzae in chronic obstructive pulmonary disease. Am J Respir Crit Care Med 2004; 169:448-53.

11 White AJ, Gompertz S, Bayley DL, et al. Resolution of bronchial inflammation is related to bacterial eradication following treatment of exacerbations of chronic bronchitis. Thorax 2003;58:680-5.

12 Wilkinson TMA, Patel IS, Wilks M, et al. Airway bacterial load and FEV, decline in patients with chronic obstructive lung disease. Am J Respir Crit Care Med 2003;167:1090-5.

13 Baneriee D, Khair OA, Honeybourne D. Impact of sputum bacteria on airway inflammation and health status in clinical stable COPD. Eur Respir J 2004;23:685-91.

14 Hill AT, Campbell EJ, Hill SL, et al. Association between airway bacterial load and markers of airway inflammation in patients with stable chronic bronchitis. Am J Respir Crit Care Med 2000; 109:288-95.

15 Wilson R. Bacteria, antibiotics and COPD. Eur Respir J 2001;17:995-1007.

16 Anthonison NR. The British hypothesis revisited. Eur Respir J 2004;23:657-8.

17 Murphy T, Sethi S, Niederman M. The role of bacteria in exacerbations of COPD (a constructive view). Chest 2000;1 18:204-9.

18 Balter MS, LaForge J, Low DE, et al. Canadian guidelines for the management of acute exacerbations of chronic bronchitis. Can Respir $J$ 2003;10(Suppl B):3-32B.

19 Saint SK, Bent S Vittinghoff E, et al. Antibiotics in chronic obstructive pulmonary disease exacerbations : a meta-analysis. JAMA 1995;273:957-60.
20 Wilson R, Kubin R, Ballin I, et al. Five day moxifloxacin therapy compared with seven day clarithromycin therapy for the treatment of acute exacerbations of chronic bronchitis. J Antimicrob Chemother 1999;44:501-13.

21 Bandi V, Jakubowycz M, Kinyon C, et al. Infectious exacerbations of chronic obstructive pulmonary disease associated with respiratory viruses and nontypeable Haemophilus influenzae. FEMS Immunol Med Microbiol 2003;37:69-75.

22 Wilson R, Allegra L, Huchon G, et al. Short-term and long-term outcomes of moxifloxacin compared to standard antibiotic treatment in acute exacerbations of chronic bronchitis. Chest 2004;125:953-64.

23 Wilson R. Outcome predictors in bronchitis. Chest 1995; 108:535-75.

24 Ball $P$, Harris $J M$, Lowson $D$, et al. Acute infective exacerbations of chronic bronchitis. Q J Med 1995;88:61-8.

25 Dewan NA, Rafique S, Kanwar B, et al. Acute exacerbation of COPD: Factors associated with poor treatment outcome. Chest 2000;117:662-71.

26 Grossman R, Mukherjee J, Vaughan D, et al. A 1-year community-based health economic study of ciprofloxacin vs usual antibiotic treatment in acute exacerbations of chronic bronchitis. Chest 1998;113:131-41.

27 Miravitlles M, Guerrero T, Mayordomo C, et al. Factors associated with increased risk of exacerbation and hospital admission in a cohort of ambulatory COPD patients: a multiple logistic regression analysis. Respiration 2000;67:495-501.

28 Miravitlles M, Murio C, Guerrero T, et al. Factors associated with relapse after ambulatory treatment of acute exacerbations of chronic bronchitis. A prospective multicenter study in the community. Eur Respir J 2001;17:928-33.

29 Niewoehner D, Collins D, Erbland M. Relation to $F E V_{1}$ to clinical outcomes during exacerbations of chronic obstuctive pulmonary disease. The Department of Veterans Affairs Cooperative Study Group. Am J Respir Crit Care Med 2000;161:1201-5.

30 Niewoehner DE, Erbland ML, Deupree RH. Effect of systemic glucocorticoids on exacerbations of chronic obstructive pulmonary disease. Department of Veterans Affairs Cooperative Study Group. N Engl J Med 1999;340:1941-7.

31 Monso E, Rosell Al, Boret $\mathrm{G}$, et al. Risk factors of lower airway bacterial colonization in chronic bronchitis. Eur Respir J 1999;13:338-42.

32 Zalacain R, Sobradillo V, Amilibia J, et al. Predisposing factors to bacterial colonisation in chronic obstructive pulmonary disease. Eur Respir J 1999; 13:343-8.

33 Wilson R, Schentag JJ, Ball P, et al. A comparison of gemifloxacin and clarithromycin in acute exacerbations of chronic bronchitis and long-term clinical outcomes. Clin Ther 2002;24:639-52.

34 Lode $\mathrm{H}$, Eller J, Linnhoff A, et al. Levofloxacin versus clarithromycin in COPD exacerbation: focus on exacerbation-free interval. Eur Respir J 2004;24:947-53.

\section{1 th European Forum on Quality Improvement in Health Care}

26-28 April 2006, Prague, Czech Republic

For further information please go to: www.quality.bmjpg.com

Book early to benefit from a discounted delegate rate 